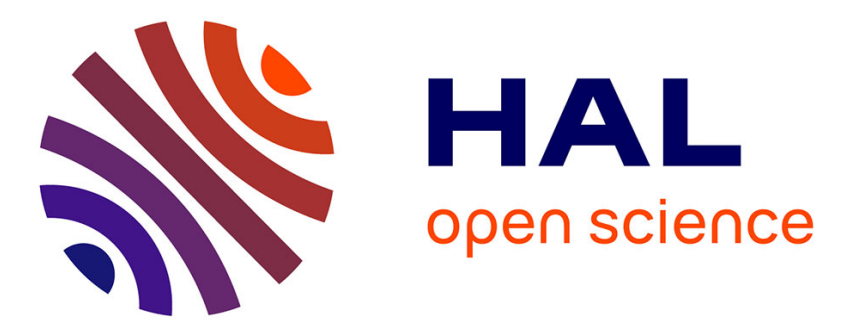

\title{
Understanding an Integrated Management System in a Government Agency - Focusing Institutional Carriers
}

Ulf Melin, Karin Axelsson, Truls Löfstedt

\section{To cite this version:}

Ulf Melin, Karin Axelsson, Truls Löfstedt. Understanding an Integrated Management System in a Government Agency - Focusing Institutional Carriers. 17th International Conference on Electronic Government (EGOV), Sep 2018, Krems, Austria. pp.15-28, 10.1007/978-3-319-98690-6_2 . hal01961532

\section{HAL Id: hal-01961532 \\ https://hal.inria.fr/hal-01961532}

Submitted on 20 Dec 2018

HAL is a multi-disciplinary open access archive for the deposit and dissemination of scientific research documents, whether they are published or not. The documents may come from teaching and research institutions in France or abroad, or from public or private research centers.
L'archive ouverte pluridisciplinaire HAL, est destinée au dépôt et à la diffusion de documents scientifiques de niveau recherche, publiés ou non, émanant des établissements d'enseignement et de recherche français ou étrangers, des laboratoires publics ou privés. 


\title{
Understanding an Integrated Management System in a Government Agency - Focusing Institutional Carriers
}

\author{
Ulf Melin ${ }^{10000-0002-2784-863 X]}$ Karin Axelsson ${ }^{10000-0003-4701-6272]}$ and Truls Löfstedt ${ }^{\text {[0000- }}$ \\ 0002-1921-7133] \\ ${ }^{1}$ Linköping University, Department of Management and Engineering, Information Systems, \\ SE-581 83 Linköping, Sweden \\ ulf.melin@liu.se karin.axelsson@liu.se truls.lofstedt@liu.se
}

\begin{abstract}
Working with an integrated management system (IMS) is a challenging task. In public organizations, the formalization of an IMS including the communication of control mechanisms, rules, goals and culture are crucial. Several types of carriers are used in order to communicate the content in an IMS - both human actors and artefacts. An artefact studied in this paper is an intranet, as one carrier of the IMS. The purpose of this paper is to explore how institutional theory - focusing institutional carriers - can help us to understand how an IMS is represented through human actors and technology in a government agency. The conclusion is that the application of an institutional carrier perspective on an IMS can help us to understand the past and present, the role, and the relative success of such a system. An IMS can be aligned or misaligned related to three dimensions of structure, process and people. Achieving an aligned and legitimate IMS is crucial in order to achieve goals in an organization. The implications of this study are that further research and practice should give more attention to institutional carriers when studying and improving IMS.
\end{abstract}

Keywords: integrated management systems, governance, institutional theory, institutional carriers, government.

\section{$1 \quad$ Introduction}

Management systems of different kinds are used in many contemporary organizations. In government organizations of today in an era of New Public Management it is commonplace. There are general management systems used in order to align individuals' activities with the overall organizational goals and mission [22] in an act of organizational coordination $[23,24]$. A general definition of a management system is that it consists of "[...] a set of procedures an organization needs to follow in order to meet its objectives" [17]. There are also dedicated management systems for management control, IT governance, quality, environment, etc. Malmi and Brown [22] define management control systems as packages, which means " $[\ldots]$ a collection or set of controls and control systems." (ibid., p. 287). Such systems can be linked to traditional accounting controls (e.g. budgets), administrative controls, and more socially oriented controls (e.g. values and culture) [22]. In this paper, we study a management system that is 
packaged and spans over a whole government agency. It contains accounting, administrative, and socially oriented control sub-systems. Since the system is considered as a package, spanning over the organization as a whole, with this integrative aim, we define the management system as integrated. Working with an integrated management system (IMS) is a challenging task in theory and in practice [18]. The complexity in the management system pose a challenge, so does the representation, use and development of it. In any organization, the formalization of the IMS and the communication of control and coordination mechanisms, rules and regulations, goals, culture and values are crucial in order to achieve goals. In the public sector we also need to recognize the complexity of values in an IMS, with e.g. competing values in internal efficiency and citizen benefit $[2,4,31]$.

In this paper, we explore the notion that several types of institutional carriers [33, 34], linked to pillars of institutions, can be used in order to analyze an IMS. This is done through the study of influential stakeholders (the management group) and the use of an intranet supporting the IMS in a government agency focused as a case in this paper. The use of carriers is a concept that stems from an institutional theory perspective. Based on an institutional perspective, information systems (IS) are artefacts carrying various types of institutionalization $[16,33]$. An IMS can also be carried by human actors, as individuals or in groups. Studying IT artefacts from this perspective within the IS domain is common and analytically promising [11, 12, 16, 28, 30], but fewer studies have explicitly explored the expressions of particular IT artefacts, like the intranet as one carrier of the IMS in our case. An institutional perspective can help us to understand the processes promoting and impeding change in organizations; processes informed by historically guided values and norms that have stabilized and persisted [29, 30]. One of few studies exploring IT artefacts, focusing on an intranet, from this perspective is provided by [5] discussing the paradox between institutionalization and awareness of the strategic value of the intranet in an organization. The authors highlight what happens when IT is embedded in the organization, as is the case with an intranet, by using an institutional theory perspective. However, they do not explicitly discuss this from an IMS perspective. To study the use and the development of an IMS from an institutional perspective is therefore interesting since it potentially can help us to understand the role of values, norms and the use of different carriers to realize the intentions of a management system when coordinating a government agency. Doing this, path dependency connects the past and the future by understanding the role of institutionalism [34, 41].

Thus, the purpose of this paper is to investigate, show and reflect upon how institutional theory - focusing on institutional carriers - can help us to understand how an IMS is represented through human actors and technology in a government agency. By applying the institutional theory perspective to the studied IMS implemented and carried by the agency's management group and an intranet we aim to understand the past and present, the role, and the challenges and relative success of an IMS. The research questions, asked, are the following: 1) how can we understand an IMS, carried by actors and IT artefacts, and its role in coordinating a government agency, and 2) what can we learn from applying institutional theory, focusing on carriers, pillars, and path dependencies from this case? The expected contributions from this paper are to broaden the 
scope on how to understand management systems applying an institutional perspective, to reflect upon the challenges and relative success of an IMS from this point of departure and the implications for future research and practice.

After this introduction, we introduce institutional theory and carriers, together with IMSs and governance in Section Two. In Section Three, we define and discuss the research approach followed by a case study introduction. Then we analyze the case by applying the institutional theory perspective to the empirical findings and formulate lessons learned from the case study in Section Four which we conclude in Section Five.

\section{Previous Research}

Below we introduce previous research on institutional theory and technology, together with integrated management systems and governance, that we also use to frame and to analyze the IMS in the case study.

\subsection{Institutional Theory and Information Technology}

Institutional theory $[29,32]$ have proven to be powerful when understanding and conceptualizing the complex nature of technology, institutional arrangements and its embeddedness in socio-economic contexts [14]. Institutions can be seen as structural arrangements that guide and restrict actors' behaviour (Berger and Luckmann, 1967). Rules of behaviour is an important dimension and range from cultural and mental models to rules in terms of legislation as well as from norms to political structures [34]. When studying and understanding institutions path dependency is an important concept connecting the past and the future in this line of research [34, 41]. Path dependency can be described as increasingly constrained processes that cannot easily be escaped when changing organizations. The concept is also considered as one answer to the question of how and why institutionalization occur [34]) - institutionalization in terms of externalization, objectification and internalization [7].

Robey and Boudreau [30] specifically suggest the use of institutional theory to understand the processes promoting and impeding change in organizations. IS researchers trying to explore the complex interplay between IT and its social context have also promoted and used institutional theory as a vehicle $[6,11,16,28]$. If we take a closer look at the digitalization of government, the role of institutional theory as a perspective to understand the complex interplay in this sector and research domain is acknowledged by e.g. $[14,21]$. From previous research, we also know that government organizations are operating based on a set of public values affecting what is possible and suitable to achieve in general and linked to the use of IT (see e.g. [4] or [31]). We choose to explore the empirical data in this paper using institutional theory, focusing pillars, carriers and path dependency, since it sheds light on the IMS and how it is carried by actors, structures and artefacts in the organization and how this has evolved over time. Based on this perspective, information systems are artefacts carrying various types of institutionalization [16, 33]. Thus, these artefacts are filled with assumptions about how government agencies should be organized. IT artefacts are not neutral; they contain additional 
ideals ascribed to them. As non-neutral artefacts they can support or impede the original intentions.

\subsection{Institutional Pillars and Carriers}

Three elements - pillars - have been considered as vital ingredients for all institutions [34]; 1) regulative, 2) normative, and 3) cultural-cognitive systems. For a more detailed description of these elements we refer to Scott [34]. Elements in institutions are conveyed by different types of carriers expressed as follows: "Institutional ideas travel in many ways. Not only are they made up of various elements [...] but they are carried by several types of vehicles." [33, p. 882]. Carriers are presented in different versions and with different labels. By using Scott [34] as a point of departure we can identify the following classes of carriers: symbolic systems, relational systems, activities, and artefacts. Institutional carriers are linked to the regulative, normative and cultural-cognitive pillars [34]. Symbolic systems can, for example, carry regulative elements (rules and laws), normative ditto (values, expectations, and standards) and cultural-cognitive elements (categories, typifications, schemas). Relational systems can carry regulative elements (governance and power systems), normative elements (authority systems), and cultural-cognitive ditto (structural isomorphism, identities). Activities as the third type of carries can be a vehicle for regulative elements (when e.g. monitoring and sanctioning), normative elements (like roles, jobs, routines and habits), and cultural-cognitive elements as a pillar like predispositions and scripts. Finally, artefacts as the last carrier can serve as a vehicle for regulative elements (objects in line with specifications), normative (objects meeting standards), and cultural cognitive elements (objects with symbolic value) [34], p. 95 f.]. Scott [33] also states that carriers are interdependent and can be combined. In the analysis below we use the different types of carriers as a theoretical perspective to investigate how an IMS is carried by a management group and an intranet. One important statement made by [33] is that the carriers as vehicles are not neutral; they effect the elements that are transported. Viewing IT artefacts as carriers is put forward by $[6,27]$.

\subsection{Integrated Management Systems and Governance}

The broad definition of management systems provided by ISO [17] can be elaborated in several different categories of management systems. Organizations also develop specific management systems over time, gathering their own processes and routines for managing certain operations. ISO notes that some systems are formalized while other systems exist entirely in the minds of individuals in the organization. Organizations that use several management systems often seek to integrate them [35]. The collected description of all operations inside an organization can be described as several connected management systems or an IMS. The idea of integrating management systems can be traced back to the desire to create management structures that are congruent and easy to maintain $[8,15]$. Another motive is to enable the best use of shared resources to meet an objective. This is another challenge that is clearly linked to the case studied in this paper - if and how to integrate several management systems into one system (an IMS). 
Jørgensen et al. [18] elaborate on the work of Wilkinson and Dale [43] and suggest a three-level model where an organization can seek to integrate management systems; “A) Corresponding: increased compatibility with cross-references between parallel systems. B) Coordinated and coherent: generic processes with focus on tasks in the management cycle. C) Strategic and inherent: an organizational culture of learning, continuous improvements of performance and stakeholder involvement related to internal and external challenges." [18, p. 714].

Management systems and the need to strategically govern processes and businesses using different IT artefacts are important in contemporary organizations in different sectors. In order to do this successfully and in a balanced way strategic alignment is suggested as one approach. Early studies emphasize that a higher degree of alignment between business and IT strategies will result in more successful organizations [40]. Strategic alignment and its results have been well-researched over the years, as broad literature reviews $[3,10,38]$ show. In recent studies the notion of IT governance has been related to strategic alignment issues. De Haes and Van Grembergen [13], for example, illustrate how IT governance has been implemented in many organizations in order to improve the alignment between business and IT. Management systems can be a tool to coordinate and control these activities and components. An organization's structures, processes, and people are important carriers of the management system, which will be further discussed below.

\section{Research Approach and Case Study Introduction}

This single, qualitative and interpretative case study [cf. 25, 42] focuses on developing empirically and theoretically grounded knowledge about IMSs in a government agency setting. This paper is written in the context of a project aiming at studying and evaluating the current management system and contributing to the foundation of a new IMS from a research-based perspective. We categorize this study as an act of engaged scholarship [39] where we combine theorizing and contributions to the government agency's problem solving.

Qualitative data collection and analysis was conducted in an iterative and reflexive manner in three stages starting with document studies to get an overview of the current management system (1). Twelve semi-structured interviews [26] where then (2) conducted over a period of two months (Jan-Feb 2015) with representatives from several business areas and hierarchical levels at the headquarters of the organization (Finance and control, Safety management, Performance management, Controlling, Information management, Communications, Operations). The semi-structured interviews were held in Swedish and quotes used in this paper are translated to English by the authors. The interviews were guided by open ended questions. In some of the interviews respondents used a live version of the intranet to demonstrate some of the IMS features and how they interpreted the implemented documents and processes. That gave us the opportunity to observe the intranet in use and how the IMS was implemented in terms of e.g. representation, design, document structure, search engines, etc. This part of the data collection was documented with a camera. Alongside this process (3) we conducted a 
hermeneutic literature review [9] to increase our understanding of the current situation and explore themes that surfaced continuously during the analysis of the data. The analysis was performed during the research period where interviews were transcribed and the responses were categorized inductively, as a part of a content analysis approach (cf. [20]). The main categories identified in the analysis were; perceptions of an IMS, structures, roles and responsibilities connected to the IMS, and the role of the IMS in the organization (how the IMS is intended to be used and is used throughout the organization). This is an example of a reflexive research process [1] working with the generation of categories based on the empirical data while using theory as a guide (e.g. institutional carriers) when analyzing data [42]. In this paper, we focus on the latter part in this reflexive research process using institutional theory as a lens and the themes emerging inductively from this analysis. In March 2015, we also conducted a workshop to validate the collected data, the initial analysis and also gathered additional data. This workshop was attended by seven representatives from the organization. A final workshop was held in June 2015 in order to present and discuss results as a part of the engaged scholarship approach mentioned above.

The setting for this case study is a government agency in Sweden with over 5000 employees spanning over several operational areas. The annual budget is over 5.5 Billion EUR (2014). The large and heterogeneous government agency uses an IMS that fills several functions in the organization. According to our respondents the IMS should depict the organizations structure and processes (and contact points in and in-between). The intention from the management group with the IMS is that it also should communicate "soft" aspects such as culture and norms. As such, the IMS should work as both control and guidance throughout the organization and in some situations also in collaboration with external resources. Influential stakeholders, such as the management group is one important carrier of the IMS, so is the intranet - the window of the IMS also carrying it and making the IMS accessible throughout the organization.

Currently the IMS consists of documentation of all operations in the organization. All the documents (approx. 4000) are published and accessible through the intranet where an overview of each business function is provided for employees. In most parts of the organization, the intranet has come to represent (become the window of) the management system as a whole. Specific actors and roles related to each business unit are responsible for keeping the documents related to their function relevant and up to date. The process of doing this is, however, carried out differently across functions. This has led to inconsistencies in notation, detail and depth of the descriptions. There are also differences in the perception of the IMS. The top management perceive the system more as a control system, whereas the employees view it as a guiding tool. This is one of the challenges that guided the analysis below.

\section{$4 \quad$ Analysis}

In this section we present our analysis of the IMS, based on institutional theory. The analysis is organized in two themes emerging from this paper's focus on how the IMS is carried: 1) the IMS and the management group carrying the IMS, and 2) the intranet 
carrying the IMS. The findings are summarized together with lessons learned from the case study linked to previous studies covering e.g. the integration dimension of the IMS, alignment, and the institutional perspective with a key focus on carriers, pillars and path dependency.

\subsection{The IMS and the Management Group Carrying the IMS}

The managerial attention toward the IMS emphasizes the necessity to have an IMS. The IMS can be characterized according to a general ISO definition [17] and can be considered as a package of controls following [22]. However, the top management and several management levels at the government agency clearly state that it is important that there is one integrated IMS present at the agency - not a package of different management systems. The IMS can have different controls, but it should be considered as one system. The reason for putting a large emphasis on the necessity of having only one IMS can be understood as a clear expression of path dependency [34, 41]. The agency merged from two rather different agencies historically (with different structures, process and organization culture) and there has been important to govern the agency as one organizational unit since then - not two. This explains the expressed need to have only one integrated IMS according to the management group, carried also by one united management group. However, the intention to have one IMS in order to merge and coordinate the agency is more alive in the strategies and the rhetoric surrounding it, than in practice. In order to realize this intention, the management group needs to carry the IMS more explicitly. This can be linked to the symbolic, relational and activity dimensions of institutional carriers. Symbolic dimension can e.g. be used to realize the regulative elements from the institutional pillars containing rules in the organization covering the need to use the IMS, normative dimensions containing values, expectations and standards (below) within the IMS communicated from management to coworkers and cultural-cognitive elements such as typifications within the IMS for different usage situations, etc. Relational systems linked to the management group carrying the IMS is a central part of the overall governance structure and processes within the government agency. Establishing legitimacy for the IMS through management's own activities following the prescribed processes (in line with e.g. prescriptions within the IMS) and rules for example is important.

The intentions linked to the IMS are multi-faceted. Listing the intentions explored in the interview data and from the document studies, empirical data involves aspects from supporting employees in their daily work, via enablers for control and monitoring, safety, legal compliance, communicating overall strategic objectives and visions, providing information on news, supporting standardized process, to describing the organization as a whole and as a vehicle to enable an active leadership. Contrasting these intentions with other interpretations and voices elaborating on whether the top management at the agency actively carries the IMS, we have identified that it is considered that the management's actions and attention are not always in line with the guidelines and the set of objectives for e.g. legitimate behaviour in the IMS. This means that the expected dimensions of carriers introduced above regarding the symbolic, relational and activity parts are not efficiently or explicitly present in management behaviour of today 
in the case. Being a legitimate carrier of a "successful" IMS requires compliance and a synchronized picture in these dimensions. One respondent at the agency expressed this in the following way when asked what the main objective of the organization was:

"Our main objective?[...] is that what is written on paper [the IMS], or what is communicated by the management?" (Business Developer, February 10, 2015)

In this example, we can see that adherence to the IMS is related to how the management group carry the IMS, how they act, and to the characteristics also of the intranet carrying (cf. [34]), communicating and legitimizing it. Regulative, normative and cultural cognitive elements of the IMS are clearly affected by different carriers, in this case human actors in different management roles in a relational dimension of the system. This was discussed during a workshop arranged at the agency. This was considered as a discrepancy between the content in the IMS and the image of the IMS and the management staff, on different levels from top to middle management. A common view here is that the management needs to have a more unified view of the IMS in the organization, the legitimacy of it, and the representation of the same system linked to different carriers (above). There is also a line of thinking describing that people in middle management and more operative roles needs to develop a further understanding of the IMS, and also legitimize it in thoughts and in daily operative work; to use the IMS as an aid to reach the overall goals in the organization. For example, people in the organization are all parts of a relational system where normative and cultural-cognitive (shared values) elements are formed and traded over time [34].

Managers carrying an IMS through behaviour and an active use of the intranet carrying it, could create a more efficient and solid alliance between human actors, behaviour and technology strengthening and legitimizing the IMS, instead of weakening it as illustrated above. This can be expressed in terms of using the directive power of an IS as an institution, and be traced back to cognitive and normative elements that are embedded in such artefacts (cf. [16]). Rules with normative forces - a kind of prescriptive behaviour - are also embedded in the system directed towards designated positions in the organization and its actors (ibid.). Starting with the management positions as examples of important roles, illustrating prescriptive behaviour and its embeddedness in the intranet carried IMS, can make the IMS more active and efficient in the organization.

\subsection{The Intranet Carrying the IMS}

In the case study, it was evident that the intranet was an important carrier [34] of the IMS. The intranet was the major representation of the IMS for many people in different roles in the heterogeneous organization performing their work. To some extent the artefact was even synonymous with the IMS (cf. $[6,27])$ - the media (the artefact) and the content focusing the different parts of the IMS were treated as one by many employees and users in the organization. When several of our respondents in the interviews and in the workshops described the IMS, they even described the functional and graphical user interface design of the intranet and thereby put the artefact in the foreground rather than the IMS. They also pointed out the importance of the design of the intranet as an artefact and a symbolic system [34], and how important it was in how well key 
information (regarding e.g. the support for routines in their daily work) was communicated in the organization as a part of management and control. This puts a lot of pressure on the overall design of the intranet being effectively designed in order to carry the IMS appropriately. Respondents kept coming back to the challenges of the design and underlying logic involved in searching for information in the IMS carried by the intranet, and to get an overview of the content relevant for them in order to be supported in their daily activities.

"The IMS contains so much information you don't know where to start looking" (Workshop participant, March 31, 2015)

"If you are not appealed by the front page [of the IMS on the intranet], you do not look at it, and finally you do not search for information there" (Manager, Finance and Control, February 09, 2015)

"Unified notation and frameworks to present information in the system are important so that the employees can navigate." (Workshop participant, March 31, 2015)

"An information-based system would make it easier to use in the organization." (Workshop participant, March 31, 2015)

The examples and citations above show how the design of the IT artefact, the intranet, in the government agency, shapes the user perceptions about the content of the system and the IMS, and also its use or non-use. The respondents also suggested many alternative ways of designing the structure of e.g. documents in the intranet. In this case the graphical user interface was commented upon as being very important, including the possibilities to search for relevant content (e.g. documents on safety or other rules or regulations), the structure of the document linked to particular work processes, etc. Properties regarding design also included for example a uniform appearance that enables recognition, the ability to personalize views based on roles in the organization or finding and defining the appropriate metadata to facilitate filtering. This would make it easier to find the appropriate documents linked to a certain area within the large and heterogeneous organization or linked to a particular task in order to get support.

As stated above we can also interpret the intranet as a symbolic system [34], thereby focusing the information stored in the system. With this perspective, we can identify important features of the intranet carrying the IMS such as a large amount of information that is difficult for users of the intranet to absorb and thereby to get supported by and managed through - one of the most important roles for an IMS. At a workshop the participants discussed the possibility of moving from the existing document-based intranet to an IMS carried by an information-based system. This was thought of as allowing more flexibility and effective communication with different types of content such as images, video and text. Once again, the design of the intranet is critical for the IMS and how it is interpreted and used within the organization. We interpret that this goes beyond the initial intention and scope of the intranet in this case study. This means that the expectations of the intranet effectivity are not met when it comes to design, use and governance intentions from the top management group.

Gosain [16] studies enterprise information systems from an institutional perspective and proposes: "[...] the view of enterprise information systems as carriers of institutionalization. Enterprise information systems represent a particular template for the conduct of the organization's activities. At the core of enterprise software packages are 
numerous assumptions about how organizational processes should work; but even with careful configuration, the fit to organizational needs is often lacking [37]. As the organization evolves over time and the assumptions built into a system's configuration stay static, this misfit has the potential to increase." (ibid., p. 168). The point of departure in this analysis of the intranet as a carrier of institutionalization also shows that the IMS as the content is a template of conduct. However, not as active as it could be regarding the legitimation of it by managers not carrying it optimally (above) and the overall design and functions in the intranet not having a good usability and representation and therefore not optimally carried by the intranet. This means that several important dimensions are not supported well enough by the intranet as the sole carrier the IMS. For example, the regulative elements are not carried enough, supporting actions in line with specifications and rules. Normative dimensions [34] in terms of standards are not communicated well enough using the IMS as a vehicle to support and govern daily work in the government agency. This also goes for the symbolic values that are expected to be a part of the IMS and the intranet in order to achieve the governance expected. As stated by e.g. $[16,19,37]$ this line of reasoning can also be associated with achieving fit between the behaviour, processes and structures in the organization and the design of the systems (the IMS and the intranet) as such longitudinally - a snapshot of fit is not enough.

\subsection{Findings and Lessons Learned - How the IMS is Carried}

Table 1 below summarizes the intentions, the present situations and the needs identified in the analysis above focusing on the IMS. The findings clearly show that the IMS could be carried more distinct and be made more legitimate by the management group and the intranet respectively in order to be effective in the organization and to govern the structure, processes and culture. The intentions are not fulfilled and several needs are identified in order to achieve a legitimate IMS governing the organization (Error! Reference source not found.).

A lesson learned from the findings in the case study is that the vision of having one integrated IMS can be questioned using an institutional perspective including path dependency [41]. One integrated management system seems to be very, or even far too, complicated to be carried by actors and artefacts (e.g. an intranet) in a large and heterogeneous organization, so the type of and level of integration is challenging [18, 43]. An aligned [36] structure and one IMS or several interlinked IMSs seem to be a critical choice regarding the challenges and relative success of management and control of behaviour in terms of relational systems, activities, and artefacts. Mirroring the findings in the present case study with Jørgensen et al.'s [18] three levels model of integrating management systems, the case is intended to be "coordinated and coherent" (model B).

Table 1. Findings summarized.

\begin{tabular}{llll}
\hline $\begin{array}{l}\text { Analytic } \\
\text { theme }\end{array}$ & Intention & Present situation & Needs \\
\hline
\end{tabular}




\begin{tabular}{|c|c|c|c|}
\hline The IMS & $\begin{array}{l}\text { One integrated } \\
\text { IMS to merge } \\
\text { and govern two } \\
\text { previously differ- } \\
\text { ent (separate) } \\
\text { agencies }\end{array}$ & $\begin{array}{l}\text { Formulated in strategy, but not } \\
\text { achieved in practice (e.g. norma- } \\
\text { tive [values and expectations] } \\
\text { and cultural-cognitive elements } \\
\text { not coherent) }\end{array}$ & $\begin{array}{l}\text { To clarify the institutional setting } \\
\text { of the IMS and to create one IMS } \\
\text { in strategy and practice or to de- } \\
\text { velop several dialects of an IMS in } \\
\text { order to align the IMS with the or- } \\
\text { ganization and the intranet (below) }\end{array}$ \\
\hline $\begin{array}{l}\text { The manage- } \\
\text { ment group } \\
\text { carrying the } \\
\text { IMS }\end{array}$ & $\begin{array}{l}\text { An actively and } \\
\text { legitimately car- } \\
\text { ried IMS }\end{array}$ & $\begin{array}{l}\text { The IMS not legitimated enough } \\
\text { by the management group sym- } \\
\text { bolically, relationally and activ- } \\
\text { ity wise }\end{array}$ & $\begin{array}{l}\text { To actively legitimate and carry an } \\
\text { IMS in order to strengthen norms } \\
\text { and values }\end{array}$ \\
\hline $\begin{array}{l}\text { The intranet } \\
\text { carrying the } \\
\text { IMS }\end{array}$ & $\begin{array}{l}\text { An actively and } \\
\text { legitimately car- } \\
\text { ried IMS }\end{array}$ & $\begin{array}{l}\text { An intranet design not support- } \\
\text { ing (not using appropriate cogni- } \\
\text { tive and normative elements em- } \\
\text { bedded in the arte-fact) and ef- } \\
\text { fectively carrying the IMS when } \\
\text { creating a shared understanding }\end{array}$ & $\begin{array}{l}\text { A redesign of the intranet to sup- } \\
\text { port the IMS focusing the structur- } \\
\text { ing of information, design, reach } \\
\text { and range in order to make use of } \\
\text { the directive power in the artefact }\end{array}$ \\
\hline
\end{tabular}

However, in practice the misaligned (Grembergen (2009) IMS is not effective and can be even counterproductive. An IMS can be aligned or misaligned in relation to the three dimensions of structure, process and people [19]. Achieving an aligned and legitimated IMS is therefore crucial - an IMS that is legitimated through actors and artefacts as combined carriers (cf. [33]). In order to have an effective IMS the case study has also shown that it is important to use the potential of the directive power of an intranet carrying the IMS. Using an intranet as an important and aligned carrier of central pillars when governing an organization, has a potential in the studied government agency. However, this demands a well-designed, well-structured, legitimate and embedded artefact, containing usability for different roles and actors within a heterogeneous organization.

The analysis of the management group at the government agency and the intranet as carriers of important elements of institution also illustrates the importance of combining and aligning carriers (in terms of e.g. relational systems [management group] and the artefact [the intranet carrying the IMS]) when trying to realize the intentions embedded in an IMS. Non-aligned and non-legitimate (misalignment according to Gosain [16]) norms, values and behaviour, for example, do not lead to a successful use of an IMS. Misalignment is shown in the case in three dimensions: 1) within the IMS as such and 2) by the management group (business) and 3) IT (the intranet) carrying the IMS. Applying an institutional theory perspective and the focus on carriers have been generative when understanding the IMS in the government agency (further elaborated below).

\section{Conclusions}

The purpose of this paper has been to investigate, show and reflect upon how institutional theory - focusing on institutional carriers with the support of pillars and path dependency - can help us to understand how an IMS is represented through human 
actors and technology in a government agency. The conclusion of this research is that the application of institutional carriers [34] as a perspective on IMSs can help us to explore and understand, in our case, a management group and an intranet as an example of an IT artefact, the role and the challenges as well as relative success of such systems. It is evident that the institutional perspective can help us to understand the symbolic and relational systems that come into play in an organization using an IMS and the human actors, routines and artefacts linked to regulative, normative and cultural-cognitive pillars within. The findings and lessons learned from the case study also lead us to the conclusion that the interplay between the general intention behind an IMS and significant actors and artefacts carrying it are highly important when governing a government agency and its structures, processes and culture. This finding is original in the context of IMS, applying institutional theory when studying human actors and an IT artefact as carriers and is one important contribution from this paper.

The conclusions show the strength of institutional theory, in terms of path dependency, when exploring IMSs - linking the present to the past [34, 41]. Addressing path dependency in this case made it possible to understand the importance and the attention that the agency management gave the aspect of having one integrated IMS - instead of e.g. heading for a more manageable and more effective IMS package (cf. [22]). It is also linked to how IT in general is governed, where the intranet in this case is an example $[13,19]$. One potential weakness of institutional theory is that the theoretical perspective can be too dominating, using distinct theoretical concepts, seeing only what the theory (as a lens) prescribes when analyzing the empirical material (cf. [42]). In the case study, however, we have tried to avoid that by using a reflexive research approach, with clear inductive parts, interpreting the empirical material more openly in the early stages, as stated in the research approach section.

The implications of this study is that further research and practice should pay more attention to institutional carriers when studying and improving IMSs. Another implication is the potential to further address human actors and artefacts carrying IMS. There is also a need to deal with the limitation that we have so far only studied one government agency in one national setting. However, we believe that the current case study is a generative example to learn from when focusing IMS and carriers, but there is a need to broaden the empirical data to also include other contexts.

\section{Acknowledgements}

This study is partially financially supported by anonymized government agency.

\section{References}

1. Alvesson, M., Sköldberg, K.: Reflexive methodology: new vistas for qualitative research, 2nd ed., SAGE, London (2009).

2. Axelsson, K., Melin, U., Lindgren, I.: Public e-services for agency efficiency and citizen benefit - Findings from a stakeholder centered analysis, Government Information Quarterly (30:1), 10-22 (2013). 
3. Balocco, R., Ciappini, A., Rangone, A.: ICT Governance: A Reference Framework, Information Systems Management (30:2), pp. 150-167 (2013).

4. Bannister, F., Connolly, R.: ICT, public values and transformative government: A framework and programme for research. Government Information Quarterly, 31(1), 119-128 (2014).

5. Baptista, J., Newell, S., Currie, W. Paradoxical effects of institutionalisation on the strategic awareness of technology in organisations, Journal of Strategic Information Systems (19:3), 171-183 (2010).

6. Barley, S.R.: Technology as an occasion for structuring: Evidence from observations of CT scanners and the social order of radiology departments, Administrative science quarterly (31:1), 78-108 (1986).

7. Berger, P. L. Luckmann, T.: The social construction of reality - A treatise in the sociology of knowledge, Anchor Books, Random House Inc., New York (1967).

8. Bernardo, M., Simon, A., Tarí, J.J., Molina-Azorín, J.F.: Benefits of management systems integration: a literature review, Journal of Cleaner Production (94), 260-267 (2015).

9. Boell, S., Cecez-Kecmanovic, D.A.: Hermeneutic Approach for Conducting Literature Reviews and Literature Searches, Communications of the AIS (34:1), 257-286 (2014).

10. Brown, A., Grant, G.: Framing the frameworks: A review of IT governance research, Communications of the AIS (15), 696-712 (2005).

11. Currie, W. Contextualising the IT Artifact: Towards a wider research agenda for IS using institutional theory", Information Technology \& People (22:1), 63-77 (2009).

12. Currie, W.L., Swanson, E.B. Special issue on institutional theory in information systems research: contextualizing the IT artefact, Journal of Information Technology (24:4), 283-285 (2009).

13. De Haes, S., Van Grembergen, W.: An Exploratory Study into IT Governance Implementations and its Impact on Business/IT Alignment, Information Systems Management (26:2), 123-137 (2009).

14. Fountain, J. E.: Building the virtual state. Information technology and institutional change, Brookings Institution Press, Washington, D.C. (2001).

15. Gianni, M., Gotzamani, K.: Management systems integration: lessons from an abandonment case, Journal of Cleaner Production (86), 265-276 (2015).

16. Gosain, S.: Enterprise Information Systems as Objects and Carriers of Institutional Forces: The New Iron Cage?, Journal of the AIS (5:4), 151-182 (2004).

17. ISO (International Organization for Standardization): Management system standards. URL: https://www.iso.org/management-system-standards.html last accessed 2018/03/16

18. Jørgensen, T.H., Remmen, A., Mellado, M.D.: Integrated management systems - three different levels of integration, Journal of Cleaner Production (14:8), 713-722 (2006).

19. Ko, D., Fink, D.: Information technology governance: an evaluation of the theory-practice gap, Corporate Governance, The international journal of business in society (10:5), 662-674 (2010).

20. Krippendorff, K.: Content Analysis: An Introduction to Its Methodology, 2 ed . SAGE Publications, Thousand Oaks (2004).

21. Luna-Reyes, L.F. Gil-Garcia, R.J.: Using institutional theory and dynamic simulation to understand complex e-Government phenomena, Government Information Quarterly (28:3), 329-345 (2011) 
22. Malmi, T., Brown, D.A..: Management control systems as a package - Opportunities, challenges and research directions, Management Accounting Research (19:4), 287-300 (2008).

23. March, J., Simon, H.: Organizations, Graduate School of Industrial Administration, Carnegie Institute of Technology, John Wiley, New York (1958).

24. Mintzberg, H. Structure in Fives: Designing Effective Organizations, Prentice-Hall, N.J. (1983)..

25. Myers, M.D.: Qualitative Research in Business \& Management, Sage Publ. (2009).

26. Myers, M.D., Newman, M.: The qualitative interview in IS research: Examining the craft, Information and Organization (17:1), 2-26 (2007).

27. Orlikowski, W.J. The duality of technology: rethinking the concept of technology in organizations, Organizational Science (3:3), 398-427 (1992).

28. Orlikowski, W.J. Barley, S.R.: Technology and institutions: what can research on information technology and research on organizations learn from each other?, Management Information Systems Quarterly (25:2), 145-165 (2001).

29. Powell, W.W., DiMaggio, P.J.: The new institutionalism in organizational analysis, University of Chicago Press, Chicago (1991).

30. Robey, D., Boudreau, M. Accounting for the Contradictory Organizational Consequences of Information Technology: Theoretical Directions and Methodological Implications, Information Systems Research (10:2), 167-185 (1999).

31. Rose, J., Persson, J.S., Heeager, L.T., Irani, Z.: Managing e-Government: value positions and relationships, Information Systems Journal, 25(5), 531-571 (2015).

32. Scott, W.R.: Institutions and Organizations, 2nd edn, Thousand Oaks, Sage (2001).

33. Scott, W.R.: Institutional Carriers: Reviewing Modes of Transporting Ideas over Time and Space and Considering their Consequences, Industrial and Corporate Change (12:4). 879-894 (2003).

34. Scott, W.R.: Institutions and organizations, 4th edn, Sage Publications Inc., London (2014).

35. Simon, A., Karapetrovic, S., Casadesus, M.: Evolution of Integrated Management Systems in Spanish firms, Journal of Cleaner Production (23), 8-19 (2012).

36. Symons, C.: IT Governance Framework, Forrester Best Practices, March (2005).

37. Talbert, N.: Getting the most from an enterprise system, MIT Sloan Management Review (44:1), 11 (2002).

38. Tallon, P.P., Pinsonneault, A.: Competing perspectives on the link between strategic information technology alignment and organizational agility: insights from a mediation model, MIS Quarterly (35:2), 463-486 (2011).

39. Van de Ven, A.H.: Engaged scholarship - A guide for organizational and social research, Oxford University Press (2007).

40. Venkatraman, N., Henderson, J.C., Oldach, S.: Continuous strategic alignment: exploiting information technology capabilities for competitive success", European Management Journal (11:2), 139-149 (1993).

41. Vergne, J-P. Durand, R.: The Missing Link Between the Theory and Empirics of Path Dependence: Conceptual Clarification, Testability Issue, and Methodological Implications", Journal of Management Studies (47:4), 736-759 (2010).

42. Walsham G.: Interpretive case studies in IS research: nature and method", European Journal of Information Systems (4:2), 74-81 (1995).

43. Wilkinson, G., Dale, B.G. An examination of the ISO 9001:2000 standard and its influence on the integration of management systems, Production Planning \& Control (13:3), 284-297 (2002). 